\title{
MJN DETERMINANTS OF FAMILY PLANNING AMONG MYANMAR WOMEN: SYSTEMATIC REVIEW
}

\author{
Nyein Moh Moh Myint*, Sa Sa Aung \\ Department of Adult Health Nursing, University of Nursing (Mandalay), Myanmar \\ *Corresponding Author's Email: nyeinmoh.1950@gmail.com
}

\begin{abstract}
Background: Family planning is achieved by using contraceptive methods and the treatment of involuntary infertility. In Myanmar, although the contraceptive prevalence rate is increasing, it still needs to reach $60 \%$ in family planning 2020 commitment. This review is aimed to explore the determinants that can improve or inhibit contraceptive usage among Myanmar women. Methods: 88 articles are found through searching in PubMed, Scopus, EBSCO and ProQuest. Nine articles which meet inclusion and exclusion criteria are selected. Results: Four main themes emerged. These are socio-demographic factors (age, level of education, marital duration, number of living children, religion, occupation, income), cognitive factors (knowledge), affective factors (attitude and motivation including support from health care providers, family, friend as well as husband and health education) and availability of service (distance form health care place, service available for 24 hours, cost). Conclusion: The findings will be supported to information about the needs and gaps in implementing family planning. It is recommended that knowledge on determinants of family planning is helpful to improve family planning program in both urban and rural communities.
\end{abstract}

Keywords: Contraceptive Usage; Family Planning; Myanmar Women

\section{INTRODUCTION}

Contraceptive usage is important for family planning (FP) to the attainment of the couples' desired number of children and the birth spacing and timing of childbirth. Moreover, it is remaining of paramount importance to women's health as preventing unintended pregnancy, and it will decrease maternal and child mortality rate (World Health Organization, 2020).

According to WHO statistics, maternal mortality ratios are higher in developing countries than in developed countries. In 2015, the maternal mortality ratio in developing and developed countries were 239 per 100,000 live births and 12 per 100,000 live births, respectively (World Health Organization, 2020). Still being a developing country, Myanmar is the secondhighest maternal mortality ratio (MMR) among ASEAN countries accounting for 282 deaths per 100,000 live births (Aung, Soe \& Moh, 2019). Almost 5\% of all pregnancies end in abortion in Myanmar (Ministry of Health and Sports, 2017a). It is estimated that onequarter to one-third of all maternal deaths would be reduced by using modern contraceptives. Therefore, contraceptive usage is essential in FP to decrease maternal and child mortality rate.

Family planning programme in Myanmar was started in one township in 1991, and then it is gradually extended to 163 out of 330 townships in 2014 (Department of Public Health, 2015). However, the prevalence of modern contraceptive usage in Myanmar is relatively lower than the other countries in Asia (Department of Economic and Social Affairs, 2015). Among the women who currently use a contraceptive, $51 \%$ of women use modern contraceptive methods, and just $1 \%$ use traditional contraceptive methods (Ministry of Health and Sport, 2017b). Although the contraceptive prevalence among married women was $52.2 \%$ in 2016 , it still needs to reach $60 \%$ in 2020 (Department of Public Health, 2015). As contraceptive use is an important role in women's reproductive health, it should explore the influencing factors regarding contraceptive usage among women. Therefore, the purpose of this systematic review is to retrieve all research related to determinants on contraceptive usage for family planning among Myanmar women. 


\section{METHODOLOGY}

This study is a systematic review following the guidelines of the Preferred Reporting Items for Systematic Reviews and Meta-Analyses (PRISMA) statement.

\section{Search Strategy}

Four electronic databases were searched: PubMed, Scopus, EBSCO and ProQuest using the following keywords: 'family planning' OR 'contraceptive use' OR 'female reproductive health' OR 'birth spacing'. Moreover, 'Myanmar' was used in all search words. Two reviewers searched independently and listed all of the articles and choose the relevant studies.

\section{Eligibility Criteria}

All qualitative or quantitative studies that focused on influencing factors regarding family planning or contraceptive use and conducted in Myanmar were considered for this review. The articles were written in English and published between 2011 and 2019. Furthermore, the researcher reviewed all referenced articles obtained from the databases to avoid the missing relevant studies. The study populations were Myanmar women, including rural and urban areas. The exclusion criteria were book chapters, conference abstract of proceeding, editorial or reports.

\section{Study Selection}

A baseline searching process is conducted in PubMed, Scopus, EBSCO and ProQuest, and 88 articles were identified. After excluding duplicated articles and the articles that did not meet eligibility criteria, nine articles were left. The complete explanation is shown in Fig 1.

\section{RESULTS}

Of the studies that met the search criteria, one is a qualitative study, eight quantitative studies. Sample sizes of all quantitative studies ranged from 222 to 1100 women, and one of them was conducted in 222 couples (222 husbands and 222 wives). In the qualitative study, the sample is 40 currently married women. Four of the studies were rural-based, two were urban, and three were mixed (rural and urban). The study areas spread all over Myanmar, namely, Mandalay Division, Yangon Division, Magway Division, Ayeyarwaddy Division and Kayin State.

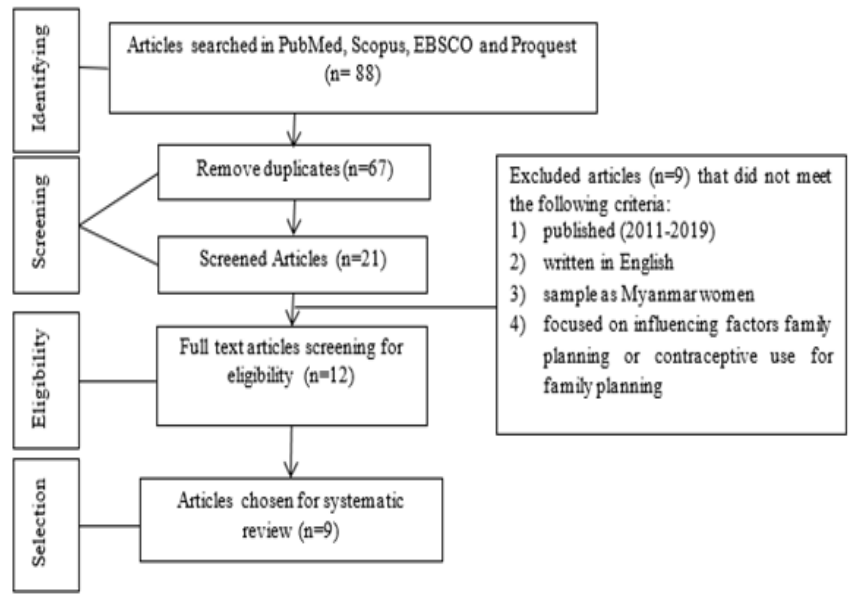

\section{Figure 1: Flow Chart of Literature Search}

Seven out of the studies described the percentage of contraceptive usage ranging from $53.4 \%$ to $87.1 \%$. Although the time and area of the study were different, the most common contraceptive methods were an injection method, followed by oral contraceptive pills among Myanmar women as described in Table 1.

Table 1: Characteristics of Articles and the Rate of Contraceptive Use

\begin{tabular}{|c|c|c|c|c|c|c|}
\hline No. & Author(s) / Year & Study Area & Sample & Research Design & \multicolumn{2}{|c|}{ Rate of Contraceptive Use (\%) } \\
\hline 1. & $\begin{array}{l}\text { Tun, Perngparn and } \\
\text { Areesantichai, } 2019\end{array}$ & $\begin{array}{c}\text { Hpa-an Township, } \\
\text { Kayin State }\end{array}$ & $\begin{array}{c}388 \\
\text { women }\end{array}$ & $\begin{array}{l}\text { Quantitative cross- } \\
\text { sectional design }\end{array}$ & 87.1 & $\begin{array}{l}\text { - Injection }(60 \%) \\
\text { - OC pills }(28 \%) \\
\text { - } \text { IUD }(4.1 \%) \\
\text { - Implant }(3.0 \%) \\
\text { - Condoms }(2.4 \%) \\
\text { - Female sterilization } \\
\\
(2.4 \%)\end{array}$ \\
\hline 2. & Wai et al., 2019 & Yangon region & $\begin{array}{c}1100 \\
\text { women }\end{array}$ & $\begin{array}{c}\text { Cross-sectional } \\
\text { study }\end{array}$ & 67.2 & - \\
\hline
\end{tabular}




\begin{tabular}{|c|c|c|c|c|c|c|}
\hline 3. & $\begin{array}{l}\text { Myint, Tiraphat \& } \\
\text { Chompikul, } 2018\end{array}$ & $\begin{array}{l}\text { Natmauk Township, } \\
\text { Magway District }\end{array}$ & $\begin{array}{c}420 \\
\text { women }\end{array}$ & $\begin{array}{c}\text { Cross- } \\
\text { Sectional study }\end{array}$ & 71.7 & $\begin{array}{l}\text { - Injection }(62.5 \%) \\
\text { - OC pill }(14.5 \%) \\
\text { - Implant }(10 \%) \\
\text { - Other }(13 \%) \\
\end{array}$ \\
\hline 4. & $\begin{array}{l}\text { Jirapongsuwan et al., } \\
2016\end{array}$ & $\begin{array}{l}\text { Aunglan Township, } \\
\text { Magway Region }\end{array}$ & $\begin{array}{c}300 \\
\text { women }\end{array}$ & $\begin{array}{l}\text { Cross-sectional } \\
\text { descriptive study }\end{array}$ & - & $\begin{array}{l}\text { - Injections }(64.1 \%) \\
\text { - OC pills }(33.6 \%) \\
\text { - IUD }(4.1 \%) \\
\end{array}$ \\
\hline 5. & $\begin{array}{l}\text { Nyein, Keiwkarnka \& } \\
\text { Sillabutra, } 2014\end{array}$ & Salin Township & $\begin{array}{c}425 \\
\text { women }\end{array}$ & $\begin{array}{l}\text { Cross-sectional } \\
\text { study }\end{array}$ & 73.3 & $\begin{array}{l}\text { - Modern contraceptive } \\
\text { methods } \\
\text { - Exclusive breastfeeding } \\
\text { method }\end{array}$ \\
\hline 6. & $\begin{array}{l}\text { Lwin, } \\
\text { Munsawaengsub \& } \\
\text { Nanthamongkokcha, } \\
2013\end{array}$ & $\begin{array}{l}\text { Hlaing Township, } \\
\text { Yangon Division }\end{array}$ & $\begin{array}{c}284 \\
\text { women }\end{array}$ & $\begin{array}{l}\text { Cross-sectional } \\
\text { survey }\end{array}$ & 75.3 & $\begin{array}{l}\text { - Injection }(71.1 \%) \\
\text { - OC pill }(58.7 \%) \\
\text { - Condom }(10.0 \%) \\
\text { - IUD }(4.0 \%) \\
\text { - Subcutaneous implant } \\
(0.5 \%)\end{array}$ \\
\hline 7. & Win et al., 2013 & $\begin{array}{l}\text { Two wards and two } \\
\text { villages, Meiktilar }\end{array}$ & $\begin{array}{c}40 \\
\text { women }\end{array}$ & Qualitative study & 74.7 & $\begin{array}{l}\text { - Most : injection, daily } \\
\text { pills } \\
\text { - Some : IUD } \\
\end{array}$ \\
\hline 8. & $\begin{array}{c}\text { Mon \& Liabsuetrakul, } \\
2012\end{array}$ & $\begin{array}{l}\text { Ayeyarwaddy } \\
\text { Division }\end{array}$ & $\begin{array}{c}222 \\
\text { couples }\end{array}$ & $\begin{array}{c}\text { Cross-sectional } \\
\text { survey }\end{array}$ & - & - \\
\hline 9. & $\begin{array}{l}\text { Zar \& Perngparn, } \\
2011\end{array}$ & Mandalay & $\begin{array}{c}358 \\
\text { women }\end{array}$ & $\begin{array}{l}\text { Quantitative } \\
\text { design }\end{array}$ & - & $\begin{array}{l}\text { - } \text { OC pills }(35.6 \%) \\
\text { - } \text { Injection }(35.1 \%) \\
\text { - } \text { IUD }(13.6 \%) \\
\text { - } \text { Implants }(1 \%) \\
\text { - } \text { Male condoms }(2.1 \%) \\
\text { - Female sterilization } \\
\text { ( } 9.4 \%) \\
\text { - } \text { Male sterilization }(3.1 \%) \\
\end{array}$ \\
\hline
\end{tabular}

* IUD: Intra-uterine devices, OC pills: Oral contraceptive pills

\section{DISCUSSION}

\section{Determinants of Family Planning among Myanmar Women}

\section{Socio-Demographic Factors}

Socio-demographic factors included age, age at marriage, level of education, marital duration, numbers of living children and desire numbers of children, religion, occupation and income.

Regarding age, one of the studies proved that contraceptive utilization was statistically significant with the age group 26-35 and the older women were less likely to use contraception than the younger age groups (Tun, Perngparn \& Areesantichai, 2019). Similarly, another study also proved that older age (risk group) more than 35 years was high in unmet need in FP (Myint, Tiraphat \& Chompikul, 2018). Besides, Jirapongsuwan et al., (2016) and Zar \& Perngparn
(2011) stated that a significant association was found between age and contraception use. It is supported to the above studies, wives aged 20-24 years were a significant predictor of the contraceptive use (Mon \& Liabsuetrakul, 2012). However, the other studies stated that age did not influence FP practice (Lwin, Munsawaengsub \& Nanthamongkokchai, 2013; Nyein, Keiwkarnka \& Sillabutra, 2014).

The women who married under 18 years old were 2.10 times more likely to have poor birth spacing than those who married at the age of 18 years or over (Nyein, Keiwkarnka \& Sillabutra, 2014). Nevertheless, Myint, Tiraphat \& Chompikul (2018) stated that there is no association between the marriage age and unmet for FP.

The study conducted by Zar \& Perngparn (2011) showed that the marital duration (more than 24 months) is higher in contraceptive utilization whereas Mon \& Liabsuetrakul (2012) rejected the association. Other 
seven studies had not described it.

Seven studies examined the association between level of education and contraceptive uses. Tun, Perngparn \& Areesantichai (2019) stated that the literate women had 5.82 times higher contraception utilization than illiterate, other six studies mentioned no association among them (Zar \& Perngparn, 2011; Lwin, Munsawaengsub \& Nanthamongkokchai, 2013; Nyein, Keiwkarnka \& Sillabutra, 2014; Jirapongsuwan et al., 2016; Myint, Tiraphat \& Chompikul, 2018; Wai et al., 2019).

Concerning income, the two studies described that adequacy of income or own income is a significant predictor of contraceptive use (Mon \& Liabsuetrakul, 2012; Jirapongsuwan et al., 2016). On the other hand, the other four studies showed that family income is no influences on contraceptive usage (Zar \& Perngparn, 2011; Nyein, Keiwkarnka \& Sillabutra, 2014; Tun, Perngparn and Areesantichai, 2019; Wai et al., 2019).

Over viewing the number of living children, Tun, Perngparn \& Areesantichai (2019) stated that the number of living children could affect contraceptive utilization and it was the highest among women who had at least one living child up to three. It is consistent with the study by Zar \& Perngparn (2011). In contrast, the number of living children and desire number of children did not influence FP practice (Mon \& Liabsuetrakul, 2012; Lwin, Munsawaengsub \& Nanthamongkokchai, 2013; Jirapongsuwan et al., 2016; Myint, Tiraphat \& Chompikul, 2018). Other socio-demographic factors; occupation (Zar \& Perngparn, 2011; Nyein, Keiwkarnka \& Sillabutra, 2014; Jirapongsuwan et al., 2016; Wai et al., 2019), religion (Zar \& Perngparn, 2011; Jirapongsuwan et al., 2016), husband's education (Nyein, Keiwkarnka \& Sillabutra, 2014) were no significant association with current contraceptive usage.

\section{Cognitive Factors}

Knowledge is the basis of cognitive skills and refers to the ability to recall or recognize the information. The women with a high level of knowledge about contraception were high in contraceptive usage (Zar \& Perngparn, 2011; Nyein, Keiwkarnka \& Sillabutra, 2014; Tun, Perngparn \& Areesantichai, 2019). Moreover, Nyein, Keiwkarnka \& Sillabutra (2014) stated that pregnant women with poor knowledge were 3.06 times more likely to have poor birth spacing than those with good or fair in knowledge. It was inconsistent with some studies that there was no association between knowledge about contraception and contraceptive usage (Mon \& Liabsuetrakul, 2012; Lwin, Munsawaengsub \& Nanthamongkokchai, 2013; Jirapongsuwan et al., 2016; Myint, Tiraphat \& Chompikul, 2018).

\section{Affective Factors}

Affective factors consist of attitude towards contraceptive usage, perception and motivation, including support from health care providers, supports from family, support from friends, receiving health education, and the number of health education received.

The attitude towards contraceptive usage is essential in changing the behaviour of women in FP practice. Five articles were found for the evidence that attitude can influence on utilization of contraceptives (Zar \& Perngparn, 2011; Lwin, Munsawaengsub and Nanthamongkokchai, 2013; Nyein, Keiwkarnka and Sillabutra, 2014; Jirapongsuwan et al., 2016; Myint, Tiraphat \& Chompikul, 2018).

Only one study mentioned regarding the perception on health belief. Mon \& Liabsuetrakul (2012) found that wife's health belief was a highly significant predictor of contraceptive use in married youths and perceived susceptibility of pregnancy and perceived barriers to contraception were independently significant predictors of contraception use.

The reinforcing factors as supports from healthcare workers, husbands and friends served to strengthen the motivation for FP practices of women. Good supports from health care providers, family, and friends were significantly associated with FP practices (Jirapongsuwan et al., 2016). Birth spacing was associated with getting information from the midwife (Nyein, Keiwkarnka \& Sillabutra, 2014). It is proved that when women got fair to good support from health workers, they practised FP 15.0 times more $(p<0.001)$ than women who got only low support (Lwin, Munsawaengsub \& Nanthamongkokchai, 2013).

Some studies showed that women with low social support from their husband and friends were more likely to have an unmet need for FP than their counterparts (Lwin, Munsawaengsub \& Nanthamongkokchai, 2013; Myint, Tiraphat \& Chompikul, 2018). Similarly, another finding supported that spousal communication was a significant predictor of contraceptive use (Mon \& 
Liabsuetrakul, 2012) and birth spacing was associated with husband's support (Nyein, Keiwkarnka \& Sillabutra, 2014). It is proved that the husband's objection was the major reason for non-use contraception (Zar \& Perngparn, 2011; Win et al., 2013).

\section{Availability of Service}

The distance and time for service available were also significant predictors. The longer the distance to obtain the contraceptive was, the lower the contraceptive use (Mon \& Liabsuetrakul, 2012). The women who got 24hour family planning services practised 3.4 times more than the women who did not available (Lwin, Munsawaengsub \& Nanthamongkokchai, 2013).

In the other hand, place to get contraception, affordability for contraceptive cost and transportation were not associated with contraceptive usage (Myint, Tiraphat \& Chompikul, 2018; Tun, Perngparn \& Areesantichai, 2019). Some women had problems with cost to obtain the method from the private sector and the time constraints of opening hours to access in the public sector (Wai et al., 2019).

\section{Other Reasons}

The most common reason for contraceptive non-use among the studied women was fear of side effects (Zar \& Perngparn, 2011; Mon \& Liabsuetrakul, 2012; Lwin, Munsawaengsub \& Nanthamongkokchai, 2013; Win et al., 2013; Nyein, Keiwkarnka \& Sillabutra, 2014; Jirapongsuwan et al., 2016; Myint, Tiraphat \& Chompikul, 2018; Tun, Perngparn \& Areesantichai, 2019; Wai et al., 2019). Others are desire to get more child, health reasons, husband objection and infrequent sex or husband being away in urban and rural areas (Zar \& Perngparn, 2011; Nyein, Keiwkarnka \& Sillabutra, 2014; Jirapongsuwan et al., 2016; Myint, Tiraphat \& Chompikul, 2018).

This review focuses on identify determinants of FP among Myanmar women. The prevalence of contraceptive use was ranging from $53.4 \%$ to $87.1 \%$. The government developed the implementation plan to meet FP 2020 commitments (60\% in the national level) (Department of Public Health, 2015) and the national and international non-government organizations also actively participated. In this study, most of the prevalence of contraceptive usage of the study areas (eight out of nine) reached the national level $(60 \%)$. Only one study area (Mandalay division) had not yet been reached. Moreover, it was higher than the contraceptive prevalence rate in the study area compared to data in the national demographic health survey (Ministry of Health and Sports, 2017b). The results showed that the contraceptive utilization proportion was varied among the states in Myanmar.

On reviewing the prevalence of contraceptive usage, it was found that rural residents were higher contraceptive use for FP than urban. Moreover, the one study area which has not yet met FP 2020 commitments was an urban area. Rural area was developing by setting up the proper roads among major villages. The accessibility to the contraceptive services in rural communities was increased even though some hours were needed to travel. Therefore, it should be more expanded up the FP program with continuous encouragement and motivation to both urban and rural communities.

Regarding the usage of contraceptive methods, although contraceptive usage in Myanmar is increasing, there were no changes in the most common methods, injection and oral pills. The finding was similar to the Myanmar country report, which showed the highest percentage was contraceptive injections, followed by birth control pills. The United Nations has reported a high prevalence of injectable contraception in Myanmar compared with other countries such as Thailand, Cambodia, Malaysia and the Philippines (United Nations, Department of Economic and Social Affairs, 2018). It may be that women considered injection because of its convenience to take only once in 3 months. Also, the injections and pills were easily accessible from pharmacies and midwives. Therefore, the pharmacists who got the training certificate and midwives should play a role in providing information or counselling regarding contraceptive.

Socio-demographic data are one of the influencing factors on FP. Age is one of the impact factors on contraceptive usage. One study showed that older age (risk group) more than 35 years was high in unmet need in FP (Myint, Tiraphat \& Chompikul, 2018). Another study mentioned that women who married at the age of fewer than 18 years tended to be poor birth spacing than over 18 years (Nyein, Keiwkarnka \& Sillabutra, 2014). Health education about contraceptive usage must give to any reproductive-aged married woman. As the consideration of age, healthcare providers should provide special attention to the older and younger age 
(less than 18 years), married women.

Regarding the educational background, a study conducted by Tun, Perngparn \& Areesantichai (2019) strongly proved that the literate women were higher in contraception utilization than illiterate. Generally, education is the vehicle to learn about health knowledge, so educated women were expected to consume more contraception. However, controversial results were found in other studies. Even non-educated women knew about contraception and were practice FP because of obtaining information about FP. Moreover, health education is important as the motivation in FP practice. Receiving health education about contraception, numbers of health education received and getting information about birth spacing are key factors contributing to contraceptive usage for FP (Nyein, Keiwkarnka \& Sillabutra, 2014; Tun, Perngparn \& Areesantichai, 2019). Therefore, providing health education involves an essential role in the family planning program among reproductive-aged women and it should be extended in providing health education about family planning in rural and urban communities.

In the two of studies, adequacy of income or own income was a significant predictor of contraceptive use (Mon \& Liabsuetrakul, 2012; Jirapongsuwan et al., 2016). Based on the results, family income was not associated with contraceptive usage. Only adequate income and own income were the predictors of contraceptive use. If women have no income to support the costs of contraception, they could not practice FP. Especially; young wives with their income may get services easier than those who have no income. Therefore, when family planning services were free of charge, women were more likely to be practice FP, and all married women should know about accessible resources for FP.

The number of living children was significantly influenced by contraceptive usage (Zar \& Perngparn, 2011; Tun, Perngparn \& Areesantichai, 2019). Moreover, many studies stated that reasons for non-use in contraception are desired to get more children. Therefore, it is needed to distribute information about family planning.

The three studies stated that if the women had high knowledge about contraception, the women are high in contraceptive usage (Zar \& Perngparn, 2011; Nyein, Keiwkarnka \& Sillabutra, 2014; Tun, Perngparn \&
Areesantichai, 2019). In contrast, some studies showed that knowledge about contraception and contraceptive usage were not significantly associated (Mon \& Liabsuetrakul, 2012; Lwin, Munsawaengsub \& Nanthamongkokchai, 2013; Jirapongsuwan et al., 2016; Myint, Tiraphat \& Chompikul, 2018). If women did not know about family planning, the incorrect use or failure in FP might be important issue. Therefore, it is needed to be further investigated.

Also, the attitude towards contraception is important in determining of practising contraception. All studies which assessed the attitude towards contraception were recommended that women with a positive attitude practised significantly in FP (Zar \& Perngparn, 2011; Lwin, Munsawaengsub \& Nanthamongkokchai, 2013; Nyein, Keiwkarnka \& Sillabutra, 2014; Jirapongsuwan et al., 2016; Myint, Tiraphat \& Chompikul, 2018). In addition, wrong perception and poor attitude regarding the risk of pregnancy resulted in a low FP practice (Lwin, Munsawaengsub \& Nanthamongkokchai, 2013). Therefore, if women get more information about contraceptive use, attitude and perception on FP will change positively and the practice also will increase among Myanmar women.

Good supports from health care providers, family, and friends were significantly associated with FP practices (Lwin, Munsawaengsub \& Nanthamongkokchai, 2013; Nyein, Keiwkarnka \& Sillabutra, 2014; Jirapongsuwan et al., 2016). Moreover, women with low support from their husbands and friends were more likely to have an unmet need for FP (Zar \& Perngparn, 2011; Mon \& Liabsuetrakul, 2012; Lwin, Munsawaengsub \& Nanthamongkokchai, 2013; Win et al., 2013; Myint, Tiraphat \& Chompikul, 2018). Hence, health education should provide for not only the women but also their partners or peers.

In addition, one study stated that pregnant women did not understand the information and contents of contraceptive usage for FP (Nyein, Keiwkarnka \& Sillabutra, 2014). Also, the findings stated that fear of the side effects of contraception was a strong influencing factor for non-use contraception. It is pointed out that women had inadequate knowledge about contraceptive utilization for family planning. Therefore, providing the information is critical to improve family planning among Myanmar women. Furthermore, providing FP services and resources 
should be a guarantee that women can properly practice family planning.

\section{CONCLUSION}

This systematic review identified the determinants on FP practice, socio-demographic factors, knowledge, attitude and perception, support from health workers, partners and friends, accessibility of services and fears of the side effects of contraceptives. Therefore, it is needed to expand up providing information for family planning in both urban and rural communities. The finding will be supported information about the needs and gaps of FP in the grass-roots community and is useful for health care providers and health authorities to design for effective FP program and further research regarding FP in Myanmar.

\section{Limitations}

This review has some limitations. First, the authors searched the articles only written in English Language. Second, only nine articles were selected for this review because of the limited search of the published articles in Myanmar. However, this review can be assumed that the first systematic review on determinants of contraceptive usage and representative to Myanmar women. It is also regional coverage of Myanmar.

\section{Conflict of Interests}

The authors declare that they have no conflict of interests.

\section{ACKNOWLEDGEMENT}

The authors would like to express our sincere gratitude to all researchers who conducted original articles for sharing knowledge and all responsible persons for completion of this review.

\section{REFERENCES}

Aung, M. S., Soe, P. P., \& Moh, M. M. (2019). Predictors of Modern Contraceptive Use and Fertility Preferences among Men in Myanmar: Further Analysis of the 2015-16 Demographic and Health Survey. International Journal of Community Medicine and Public Health, 6(10), 4209-4217.

Department of Economic and Social Affairs. (2015). Trends in Contraceptive Use Worldwide 2015. https://www. un.org/development/desa/pd/sites/www.un.org.development.desa.pd/files/undesa_pd_report_2015_trends_contr aceptive_use.pdf

Department of Public Health (2015). Costed Implementation Plan to meet FP2020 Commitments Myanmar 2014. https://www.familyplanning2020.org/sites/default/files/FPAP-April-2015-formatted_30June2015_wtsignature.pdf

Department of Economic and Social Affair (2018). World Contraceptive Use 2018. https://www.un.org/ en/development/desa/population/publications/dataset/contraception/wcu2018.asp

Jirapongsuwan, A., Latt, K.T., Siri, S., \& Munsawaengsub C. (2016). Family Planning Practice among Rural Reproductive-Age Married Women in Myanmar. Asia-Pacific Journal of Public Health, 28(4), 303-312.

Lwin, M. M., Munsawaengsub, C., \& Nanthamongkokchai, S. (2013). Factors Influencing Family Planning Practice among Reproductive Age Married Women in Hlaing Township, Myanmar. Journal of the Medical Association of Thailand, 96(Suppl 5), 98-106.

Ministry of Health and Sports. (2017a). Myanmar Family Planning Landscape Analysis. https://www. familyplanning2020.org/sites/default/files/Jhpiego-FP2020-FP-Landscape-Analysis_final-approved.pdf

Ministry of Health and Sports. (2017b). Myanmar Demographic and Health Survey 2015-16. https:// dhsprogram.com/pubs/pdf/FR324/FR324.pdf

Mon, M. M., \& Liabsuetrakul, T. (2012). Predictors of Contraceptive Use among Married Youths and Their Husbands in a Rural Area of Myanmar. Asia-Pacific Journal of Public Health, 24(1), 151-160.

Myint, A. H., Tiraphat, S., \& Chompikul, J. (2018). Determinants of the Unmet Need for Family Planning among 
Married Fecund Women in Natmauk Township, Magway Region of Myanmar. Journal of Public Health and Development, 16(2), 41-57.

Nyein, C., Keiwkarnka, B., \& Sillabutra, J. (2014). Factors Affecting the Birth Spacing Among Rural Pregnant Women in Salin Township, Myanmar. Journal of Health Research, 28(3), 165-171.

Tun, S., Perngparn, U., \& Areesantichai, C. (2019). Factors Affecting Utilization of Family Planning Services Among Married Women of Reproductive Age Living in the Rural Area of Kayin State, Myanmar. International Journal of Multidisciplinary Research and Publications, 2(1), 7680.

Wai, M. M., Bjertness, E., Stigum, H., Htay, T. T., Liabsuetrakul, T., Myint, A. N. M., \& Sundby, J. (2019). Unmet Need for Family Planning Among Urban and Rural Married Women in Yangon Region, Myanmar: A Cross-Sectional Study. International Journal of Environmental Research and Public Health, 16(19), 3742.

Win, Y. Y., Lwin, A. M. M., Aung, T., Maung, C. N., Toe. M. M., Myint, Y. Y., \& Oo, H. N. (2013). Currently Married Urban and Rural Women in Meiktila Township: Qualitative Study on Contraceptive Use. The Myanmar Health Sciences Research Journal, 25(2), 143-148.

World Health Organization (2020). Family Planning/Contraception Methods. https://www.who.int/en/newsroom/fact-sheets/detail/family-planning-contraception

Zar, K. T. \& Perngparn, U. (2011). Contraception usage among married women of reproductive age in Mandalay, Myanmar. Journal of Health Research, 25(2), 101-103. 